\title{
Concentration and Purity DNA Spectrophotometer: Sodium Monofluorophosphate forensic impended effect
}

Simon Martin Manyanza Nzilibili ${ }^{1,2^{*}}$, Moh. Kurniadi Hendry Ekodiyanto ${ }^{1}$, Pudji Hardjanto ${ }^{1,3}$ and Ahmad Yudianto ${ }^{1,4}$

\begin{abstract}
Background: A number of factors have been identified to affect DNA analysis for forensic purposes. SMFP compound which is constituted in toothpaste is one of those factors identified to cause this effect. The impact of this compound in forensic science is far evidenced to contaminate, inhibit and destroy biological samples. Toothbrush, one of preferable forensic evidences to recover biological sample in contact (brushing); might not be useful in identifying an individual if the person used toothpaste of SMFP compound. The SMFP reaction leads to inhibited band visualisation, concentration and purity contamination that lead to a failed analysis. This study presents experimental observational findings on the detrimental effects of the compound on DNA concentration and purity profiled from sample recovered from toothbrush.
\end{abstract}

Results: Using spectrophotometer with complementary findings from electrophoresis, it was found that among the ten samples analysed one sample had extreme DNA concentration of $371 \mu \mathrm{g} / \mathrm{ml}$ with minimal purity measurement A260/A280 ratio of 1.25. Concentration analysed portrays the detrimental effect that damage and destroy DNA molecules into increased segmented molecules. Purity readings suggest the lowered amount of intact DNA molecules that would be enough to make into PCR. Also, PCR and electrophoresis method portrayed inhibition and failed visualisation of sex gene band contrast. Twofold phenomena emerged: limited DNA targeted locus for electrophoresis and DNA ionic irresponsive interactions. These are suggested by a twofold causation; one being non-polymerisation of the targeted DNA region and the other was destructed molecular structure acted by SMFP respectively.

Conclusion: SMFP compound impedes concentration and purity of DNA physical samples, thereby affecting the physical sample by hindering forensic profiling through damaging DNA molecule to a no applicability and acceptability state. These findings verdict contributes to the understanding of SMFP constituted toothpaste action on biological sample during DNA forensic analysis.

Keywords: Concentration, DNA, Forensic science, Purity, Sodium Monofluorophosphate, Spectrophotometer

\footnotetext{
* Correspondence: nzilibili@gmail.com

${ }^{1}$ Forensic Science Program, Post Graduate School, Airlangga University, 4-6 Airlangga Rd, Surabaya 60286, Indonesia

${ }^{2}$ Division of Nursing and Midwifery Services, Ministry of Health, Community

Development, Gender Elderly and Children, 6 Samora Machel Avenue, 11478

Dar es Salaam, Tanzania

Full list of author information is available at the end of the article
} 


\section{Background}

Deoxyribonucleic acid (DNA) purity and concentration from toothbrush for forensic intent is encountered by a number of factors including the used toothpaste constituents like Sodium Monofluorophosphate (SMFP) and Sodium Fluoride (NaF) compounds (Volpe et al. 1995). Furthermore, fluoride dominates besides being known of its detrimental effect. The detrimental effects of fluoride have been established to include DNA damage (Zhang et al. 2008; Song et al. 2015) as well as destruction by destabilisation of its molecule through hydrogen bonds break as reported by Yiamouyiannis (1998) in the work titled "fluoride, the silent killer". For SMFP compound in toothpaste, literature has suggested that there is an effect caused by the compound in profiling DNA for forensic purposes (Volpe et al. 1995; Yiamouyiannis 1998; Alfadaly et al. 2016; Agency for Toxic Substances and Disease Registry 2003; Song et al. 2015). Such effect is also manifested in DNA extraction from toothbrushes with SMFP compound (Adams et al. 2017; Alfadaly et al. 2016). Therefore this effect might contribute to problematic and challenging identification on individualised investigation.

Although the damaging effect of SMFP compound has been substantiated to a varied extent but to the best of the authors' knowledge the effect has not yet been individualised to concentration and purity of DNA profile. This therefore, appeals to matters related to law-suit through forensic DNA where concentration and purity is demanded at all time (Hedman et al. 2010; Khare et al. 2014; National Research Council 2011; Olson and Morrow 2012; Oxford Gene Technology 2011). This interrogated intactness of such analysed DNA sample results in ascertained profile due to absence, insufficiency, degraded or inhibited state (Leary 2012). Consequently, profiling potentially damaged, degraded, inhibited or compromised DNA samples lead to jeopardized applicability of the expected results (Arbeli and Fuentes 2007; Lawless 2009; Leary 2012; National Research Council 2011; Niemi et al. 2001; Vandewoestyne and Deforce 2010).

In order to substantiate the noted and reported act of SMFP on DNA molecule that would subsequently affect DNA analysis when proving criminality of event during forensic investigation. This study dedicated its assessment in understanding the effect of the SMFP compound in toothpaste towards concentration and purity of DNA profiled on sample recovered from toothbrush. The findings are expected to inform and trigger future dealing with such sample for continued successful DNA profiling.

\section{Materials and methods}

The experiment of this study was conducted at the Human Genetic Laboratory of the Airlangga University involving samples obtained from ten volunteers.

\section{Sample preparation}

The study involved ten volunteers (6 men and 4 women Tanzanians living in Surabaya) who agreed and consented to participate in the study after a detailed explanation of the aim of the study. In order to get the required biological sample for the experiment, volunteers were instructed to twice a day regular and routine tooth-brushing which was done in their home place as usual. To control the study, brushing was done using new similar labelled toothbrushes that were given to the volunteers together with the same SMFP contained Colgate $^{\circledast}$ toothpaste. The concentration of the SMFP as active ingredient in the toothpaste used was $1.1 \%$ (1450 ppm of Fluoride) (Fig. 1e). After instruction and handling of required items to volunteers, then the experimental process became preceded by a seven (7) day brushing. Thereafter, samples were collected in the morning of the eighth day, packed well in sterilized paper envelope and transported to the laboratory ready for experiment.

\section{DNA extraction}

DNA extraction process started by an overnight soaking of the toothbrush bristles separately in 10 sterile centrifuge tubes (Fig. $1 \mathrm{~b}$ and $\mathrm{c}$ ). The sterile tubes were each filled with $8 \mathrm{~cm}^{3}$ of distilled water to allow dissolution and settling of the DNA biological sample logged on the toothbrush bristles. From 10 collected soaked solutions of biological samples, the supernatants fluid were removed and left with down settled DNA sample solution from which a $0.5 \mathrm{~cm}^{3}$ of every sample was pipetted into another new sterile centrifuge plastic tube. A $1 \mathrm{~cm}^{3}$ DNAzol (Invitrogen, ThermoFisher Scientific, Waltham, MA, USA) was added, vortexed and incubated for $15 \mathrm{~min}$; then, $0.2 \mathrm{~cm}^{3}$ of Chloroform (Merck KGaA, 64271 Darmstadt, Germany) was added, vortexed and incubated again for $15 \mathrm{~min}$ followed by a centrifuge at $8000 \mathrm{rpm}$ for $10 \mathrm{~min}$. After centrifuge, the above separated supernatant was obtained with care into eppendorf which was then mixed with isopropanol (EMSURE ${ }^{\oplus}$, Merck KGaA, 64271 Darmstadt, Germany) $1 \mathrm{~cm}^{3}$ and incubated again for $15 \mathrm{~min}$. Centrifugation followed again, at 12,000 rpm for $10 \mathrm{~min}$. Supernatant fluid was removed carefully without touching the pellet on the tube wall. The left pellet was washed with $0.5 \mathrm{~cm}^{3}$ of $70 \%$ ethanol (EMSURE ${ }^{\ominus}$, Merck KGaA 64271 Darmstadt, Germany) and incubated for $15 \mathrm{~min}$, and then similar centrifuge $(12,000 \mathrm{rpm})$ repeated for 5 min which led to the removal and discard of the formed supernatant again; protocol followed Chen et al. (2010) as well as Chomczynski et al. (1997). At the final point, $50 \mu \mathrm{l}$ of distilled water was added to re-suspend formed pellet then vortexed to make ready volume of DNA pellet for Polymerase Chain Reaction (PCR) and spectrophotometer. 


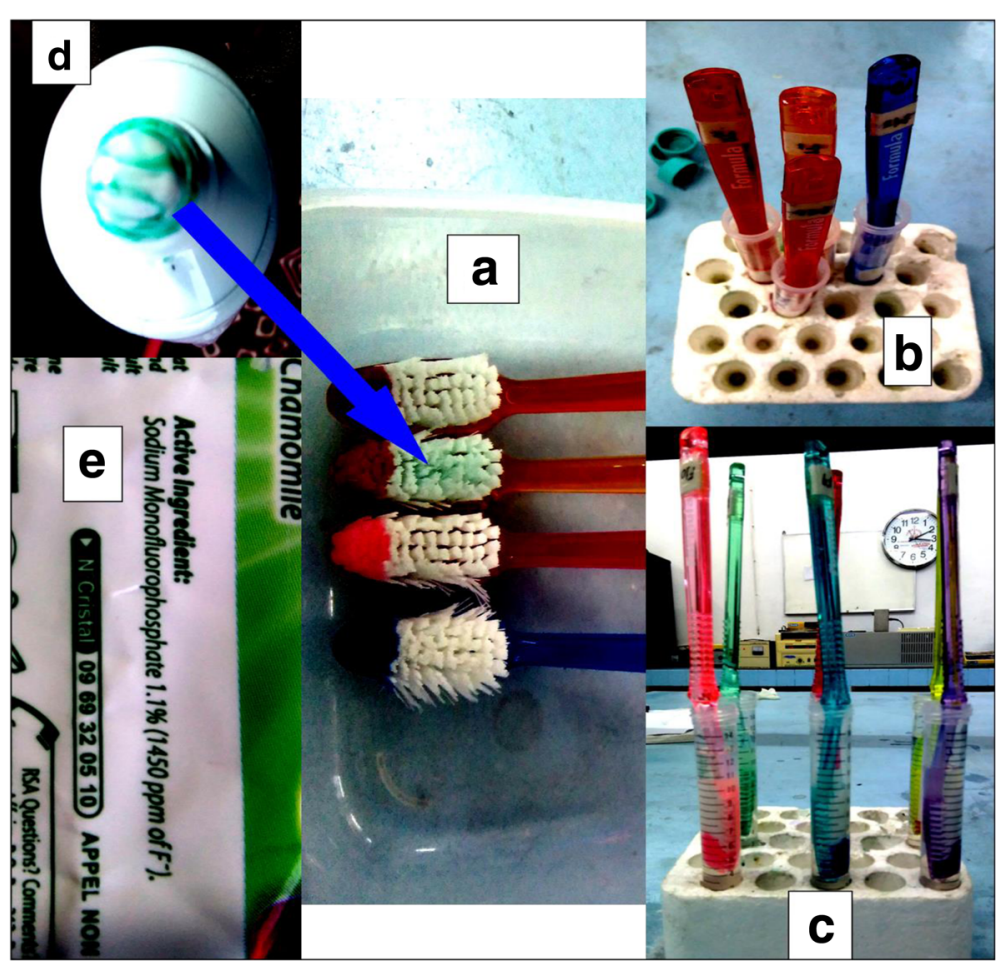

Fig. 1 Examination of the greenish colour marked on toothbrush during recovery of DNA sample. The greenish colour observed on the toothbrush recovered for DNA analysis prompted to the examination of the associated effect. Colour observed correlated with the colour of the toothpaste provided that remained concentrated in bristles. During examination of the greenish colour the SMFP compound was found. Sequential examination made during DNA sample recovery is sectioned as it appears in; a Introduce toothbrushes evidences with detected deep colour (greenish) compared to other toothbrushes. b Sample recovery through soaking was conducted carefully while tracing the marked sample. c Displays bristles immersed in tubes with distilled water to allow down settling of sample from toothbrushes. $\mathbf{d}$ Cross matching of, colour concurred. e Submits SMFP compounded toothpaste, further analysis to continue establish consequences on forensic DNA

\section{Observation of intent to the study}

In processing the sample from collection for DNA extraction, an observation was made in one toothbrush (Fig. 1a-e) , the diverted observation was the greenish colouration of the toothbrush bristles among the other toothbrushes. Greenish colour was alike the used toothpaste given to the volunteers for a 7 days brushing (day and night) upon comparison. The evaluation suggested a pilled amount of toothpaste (containing SMFP) left probably due to partial rinse after brushing. Such uniqueness furthered investigation to examine potential effects on DNA concentration, purity and band contrast that might be associated. This effort is a realisation that the compound (SMFP) constituting the used toothpaste, which according to studies carried out; is established to have a significant effect on DNA at increased amount (Song et al. 2015).

\section{Concentration and purity of DNA}

From final extracted and prepared DNA volume $(50 \mu \mathrm{l})$ a portion was divided to run for DNA quantification. Quantification aimed at determining potential findings that would be of interest with reference to SMFP effect in response to observation made. Using
Ultraviolet-visible Spectrophotometer (UV-1601, PC, Shimadzu, Japan), the procedure was as follows;

\section{DNA concentration}

Through $260 \mathrm{~nm}$ (Optical density - OD) light absorbance, DNA concentration measured at 70 dilution factor prepared from $10 \mu \mathrm{l}$ DNA and $690 \mu \mathrm{l}$ distilled water was as calculated as follows $(1.0=50 \mu \mathrm{g} / \mathrm{ml}$ pure double stranded DNA (dsDNA)) (Promega 2014);

- DNA Concentration was given by absorbance reading at $260 \mathrm{~nm}$ and 280 in UV-1061.

\section{DNA purity}

- Purity was estimated by the Optical Density (OD) OD260/OD280 ratio.

\section{Polymerase Chain Reaction (PCR)}

Samples were polymerized using common Amelogenin gene (Promega Corporation, Madison, USA) to determine SMFP impended effect through electrophoresis visualization of band contrast in complement with spectrophotometer 
measurement method. This PCR analysis was by BIO RAD $\mathrm{T}^{100}{ }^{\mathrm{mix}}$ Thermal Cycler. A $12.5 \mu \mathrm{l}$ of PCR mix (Promega Corporation, Madison, USA) using a set of - primers (forward: 5'CCCTGGGCTCTGTAAAGAA-3' and reverse: 5'ATCAGAGCTTAAACTGGGAAGCTG-3') for amplification of a $106 \mathrm{bp}$ and a $112 \mathrm{bp}$ fragment from the amelogenin gene in $\mathrm{X}$ and $\mathrm{Y}$, respectively, was used (Sullivan et al. 1993). A $1 \mu \mathrm{l}$ of DNA was used from each of the 10 samples then $6.5 \mu \mathrm{l}$ nuclease (Promega Corporation, Madison, USA) free water was added at $8.5 \mathrm{pH}$ before spin.

\section{Electrophoresis}

Electrophoresis was run after preparation of the acrylamide gel. The gel was prepared from $3 \mathrm{~cm}^{3}$ acrylamide reagent (Sigma-Aldrich) mixed with $8 \mathrm{~cm}^{3}$ Tris-borate-EDTA (TBE) Buffer $0.5 \times$ (Promega Corporation, Madison, USA) into erlenmayer, homogenised then temed (Sigma-Aldrich) $20 \mu \mathrm{l}$ and homogenized again. A $200 \mu \mathrm{l}$ ammonium perisulfate solution (Sigma-Aldrich) was added followed by homogenization in the erlenmayer also. Prepared solution gel became inserted into the existing electrophoresis chamber of $0.5 \times$ TBE buffer solution. At last a $5 \mu \mathrm{l}$ PCR DNA sample volume was pipetted into gel column. After introduction of the solution, electrophoresis set at 100Volts for $60 \mathrm{~min}$ to allow DNA migration from negative to positive charged opposite end that later became visualised as band contrast.

\section{Measures taken and considered to control the study}

Intended DNA profiling is subjected to contamination when foreign and un-targeted genetic material gets in contact with. In order to ensure reliability of the study's findings, several measures were taken into account with inclusion of; sterilisation of envelope for packaging of toothbrush sample evidence to laboratory, maintained laboratory room temperature at $26.5{ }^{\circ} \mathrm{C}$, use of Personal Protective Equipments/gears (PPE - gloves, lab coat, mask). Other measures included application of sterile equipment, use of annually maintained and calibrated machines together with twice a week sterilization and disinfection of the laboratory room by Ultraviolet lamps.

\section{Results and discussion}

\section{Concentration and purity quantified interference of DNA}

Concentration and purity implication assessed by established interference of SMFP in DNA through the use of spectrophotometer. Concentration and purity parameters measured significant variation as presented in Table 1. Findings of sample "a" read at extremity of all the ten samples which means the DNA of sample "a" was affected by the constituted compound; SMFP. The damage and degradation extent caused by SMFP composites in the used toothpaste is presented by a DNA concentration of 371 at a purity ratio of 1.25 (Table 1 ).
This signifies a lost and disrupted DNA intactness. Considering other sample readings, the similar compound might have acted too, each according to the extent embedded thus making some values closer to the marked sample as presented in Table 1. Referencing $1.6-2.0$ margin of acceptable quality DNA for forensic analysis, literature also suggests interference of Ribonucleic acid (RNA) and protein in substantiating the outlier values (Khare et al. 2014; Oxford Gene Technology 2011).

All of sample readings are at increased risk action of the two factors, RNA and protein readings and even SMFP except sample "g" which was found in the purity limit. The difference here is on the available concentration and amount of detrimental compounded toothpaste logged in the toothbrush forensic evidence as supported by Song et al. (2015). Understanding potential detrimental effect on DNA forensic sample and tracing its cause help to establish consciousness in handling such sample when in contact for defining forensic inquiry. Delineating concentration and purity of DNA for forensic application is vital for reliability, reproducibility and profile interpretation of the sample in relation to the crime and DNA related queries (Oxford Gene Technology 2011). Results observed and analysed from this study motivated attainment of the associated effect from sample collected through spectrophotometer's assessment (Table 1).

\section{PCR and electrophoresis latent inhibition}

SMFP degradation and destruction effect on DNA subject the molecules split up into small molecules. Small degraded molecules appear accumulated in high amount in the sample solution and when measured; the concentration readings elevated more than the intact DNA molecules as portrayed by sample "a" in Table 1 . This means that there is interrupted DNA molecules integral structure. Destroyed molecular structure suggests a prevented detection of the targeted locus to be amplified and polymerised. The effect outcome is inhibited action of Amelogenin gene primer that is targeted to amplify Amel gene of particular sex in order to determine sex of the volunteers. The consequence is also transferred to electrophoresis inhibition and limited band contrast formation in Fig. 2, sample "a". Non-polymerisation of the targeted molecule region contributes to a twofold electrophoresis limitation, another being the destructed molecular structure acted by SMFP.

The twofold interfering probabilities provide two phenomena that can lead to failed electrophoresis on particular sample DNA. The first phenomenon is the limited amount of DNA targeted locus due to nonpolymerisation of the molecule and the second is DNA ionic irresponsive interactions caused by destruction of molecular structure. The phenomenon above limit migration of molecule formed fragments to respective 
Table 1 Concentration and Purity of DNA obtained from measured samples in relation with the effect of SMFP

\begin{tabular}{llllll}
\hline Sample code & Sample sex & $\mathrm{OD}_{260}(\mathrm{~nm})$ & $\mathrm{OD}_{280}(\mathrm{~nm})$ & DNA concentration $(\mu \mathrm{g} / \mathrm{ml})$ & DNA purity \\
\hline "a" & Female & 0.106 & 0.085 & 371 & 1.25 \\
"b" & Female & 0.044 & 0.033 & 56 & 1.33 \\
"c" & Male & 0.016 & 0.007 & 87.5 & 2.29 \\
"d" & Male & 0.025 & 0.016 & 112 & 1.56 \\
"e" & Male & 0.032 & 0.021 & 161 & 1.52 \\
"f" & Male & 0.048 & 0.035 & 101.5 & 1.37 \\
"g" & Male & 0.029 & 0.018 & 84 & 1.61 \\
"h" & Male & 0.024 & 0.016 & 196 & 1.5 \\
"i" & Female & 0.056 & 0.041 & 136.5 & 1.37 \\
\hline "j" & Female & 0.039 & 0.027 & 1.44 \\
\hline
\end{tabular}

Ascertained implication was assessed by establishing quality and quantity parameters to support the suggested effect of SMFP. The spectrophotometer measured parameters: concentration and purity corresponded to the degree of toothpaste remains in the toothbrush. Greenish coloured sample "a" presented the highest amount of DNA concentration $(371 \mu \mathrm{g} / \mathrm{ml})$ under $\mathrm{OD}_{260}(\mathrm{~nm})$ Absorbance while in return, purity measured the lowest level $(1.25)$ of other samples signifying a lost DNA intactness by SMFP. Sample "a" shows that the SMFP effect increases as the amount of compounded toothpaste increases

electric field under electric conduction. As a result the analysis profile six male, three female with one unknown which is female according to volunteers participated (Fig. 2). Some findings also refer to cellular components dilution as also a factor to inhibit contrast. Having noted that dynamicity also, the study applied (to both samples) similar final volume of 50 and pipette dilution factor of 70 at double stranded DNA molecules of $50 \mu \mathrm{g} / \mathrm{ml}$ constant to 1.0 (Oxford Gene Technology 2011); this uniformity challenges component dilution factor. Thus, un-revelation of sample "a" due to inhibited band contrast formation agree with the effect caused by SMFP hence interfered forensic identification and individualisation.

\section{SMFP impending forensic profiling and proofing}

Destructive, inhibition and damaging effect of toothpaste SMFP compound on DNA is both manifested on spectrophotometer (Table 1) and also on electrophoresis (Fig. 2). Thereby; each method's presentation, potentiate and parallel interference of SMFP on DNA molecule. Interfered DNA analysis to profile inquired forensic sample "a" impend investigation of a raised criminal inquiry. Sample admissibility for jury proceedings also becomes questionable

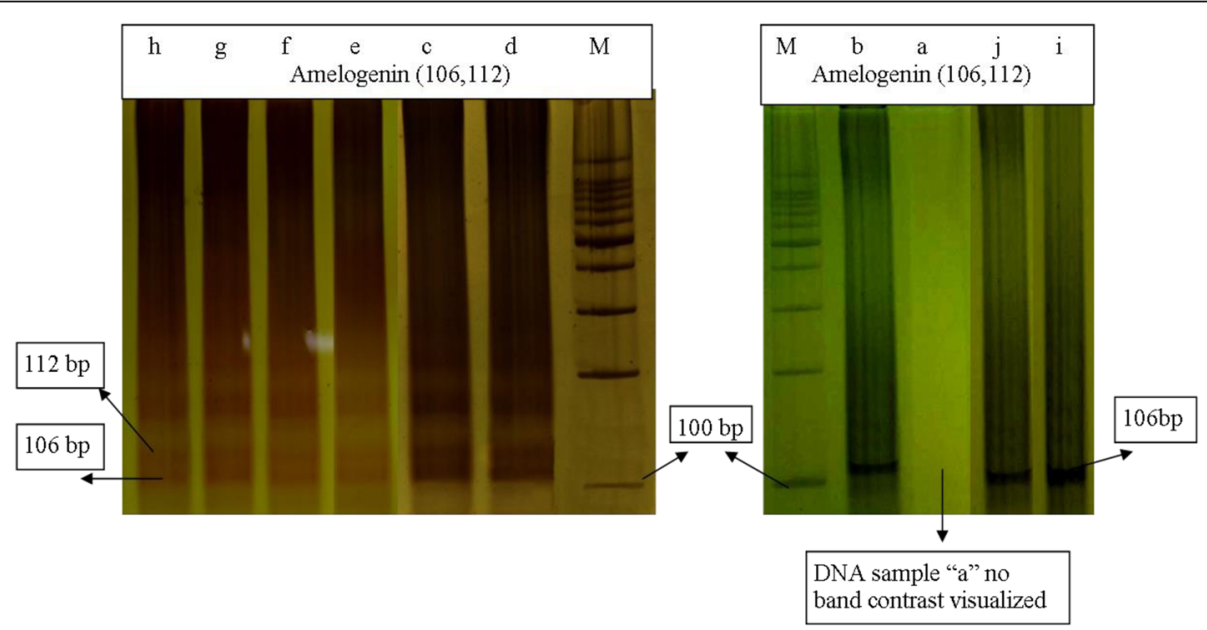

Fig. 2 Electrophoresis DNA band contrast visualisation with inhibited formation in sample "a" in relation to SMFP compound. The SMFP toothpaste concentrated in toothbrush was found to degrade and interfere DNA that became inhibited to migrate in electrophoresis. Damage led to insensitivity DNA ionised molecule in electric flow to opposite positive end. The effect is depicted by without base band formation, hence no visualised contrast compared to other nine samples. As a result, the analysis profile 6 male, three female with the one unknown which is female according to volunteers participated. Masked band contrast present, confirms and contributes to impended effect of SMFP comparably with spectrophotometer findings 
as due to suspicious proof caused by intrusion of the foreign substance, SMFP. Despite the findings obtained in correspondence to the observation made from sample collection and isolation, necessity of analysis and further observation on sample "a" beyond concentration and purity remained. This explorative examination institutes a tally correspondence of greenish colouration on toothbrush to toothpaste used. The presence and remaining of reasonable amount of toothpaste on that toothbrush compromised and interfered DNA profiling. This is mentioned as per molecular structure destruction and non-polymerisation effect that result in irresponsive ionic migration and limited DNA targeted locus respectively.

\section{Conclusion}

Proceeding with forensic DNA profiling, DNA concentration and purity parameters assurance remain important in order to have desirable results. This study's assessment between the parameters from toothbrush logged DNA biological samples with SMSP revealed associated interference. The findings analysed link the effect extent with amount of SMFP (in toothpaste) acting on such sample as presented in Fig. 1: a and Table 1. This amount dependency defines the presented meaning of impended effect relation. To this far, SMFP through DNA degradation is affirmed to substantiate molecular structure destruction and polymerisation inhibition. Such destruction and inhibition as a result interfere DNA concentration, purity and even band visualisation for forensic applicability. The findings of this study therefore conclude availability of impending effect from SMFP on DNA concentration and purity, hence a treat with care alert when dealing with such evidence but also triggering information to innovation.

\section{Abbreviations}

bp: Base pair(s); DNA: Deoxyribonucleic acid; dsDNA: Double stranded DNA; NaF: Sodium Fluoride; OD: Optical density; PCR: Polymerase chain reactions; RNA: Ribonucleic acid; SMFP: Sodium Monofluorophosphate; TBE: Tris-borateEDTA

\section{Acknowledgements}

Authors wish to extend gratitude to all those participated in supporting this piece of work accomplished; in a special way, we appreciate the technical support from Indah and Ayuu of the Human Genetic Laboratory, Airlangga University and advisory supervision of Dr. Ahmad Yudianto in taking us this far.

\section{Funding}

This research received no specific grant from any funding agency in the public, commercial, or not-for-profit sectors.

\footnotetext{
Availability of data and materials

Data results from secondary observation (observed to be of interest) made to a primary study, data of the primary study will not be shared because of being used in the primary study furthermore, the secondary observation satisfy themselves as standing observed deviance that interested to compile this article.
}

\section{Authors' contributions}

SMMN structured the conceptualized study and contributed significantly in carrying out the experiment data interpretation and manuscript preparation. $\mathrm{PH}$ and MKHE contributed equally towards designing and carrying out of experiments, data analyses and in manuscript preparation. AY conceptualized the study provided critical and valuable technical advisory content for accomplishment of the work and data processing. All authors read and approved the final manuscript.

\section{Authors' information}

Simon Martin Manyanza Nzilibili, RN, BScN, is a placement and capacity building officer at the Ministry of Health, Community Development, Gender, Elderly and Children in the Division of Nursing and Midwifery Services, Tanzania. Well experienced in policies, guidelines and SOPs development; supervising, mentoring, supporting and paving nursing developmental opportunities in improving nursing and general health care. Currently; Masters candidate in Forensic Science at the Post-graduate School of the Airlangga University, Surabaya - Indonesia; prepared to linking scientific and health/medical principles to community demanded criminal, civil and societal inquiries.

Moh. Kurniadi Hendry Ekodiyanto, Holder of Bachelor of Science in Nursing with experience in community youth institutional league. Currently; Masters candidate in Forensic Science at the Post-graduate School of the Airlangga University, Surabaya - Indonesia; visioned to crime scene investigation and human identification.

Pudji Hardjanto, LLB and trained Police Officer and Crime Scene Investigator. Experience in a crime scene investigation in the police forces criminal and investigative department since 1994, finger print, crime scene and human identification visiting and honorary teacher. Currently; Masters candidate in Forensic Science at the Post-graduate School of the Airlangga University, Surabaya - Indonesia.

Dr. Ahmad Yudianto, PhD, MMed, MD, Forensic Science and medico-legal Specialist. Is a Lecturer and head of the Forensic Science Master Program of the University of Airlangga since 2010/11 and Specialist Doctor's education program since 2015. Researcher in Human Genetics; forensic, medico-legal and expert witness since 2007.

\section{Competing interests}

The authors declare that they have no competing interests.

\section{Publisher's Note}

Springer Nature remains neutral with regard to jurisdictional claims in published maps and institutional affiliations.

\section{Author details}

${ }^{1}$ Forensic Science Program, Post Graduate School, Airlangga University, 4-6 Airlangga Rd, Surabaya 60286, Indonesia. ${ }^{2}$ Division of Nursing and Midwifery Services, Ministry of Health, Community Development, Gender Elderly and Children, 6 Samora Machel Avenue, 11478 Dar es Salaam, Tanzania. ${ }^{3}$ Criminal Investigative Unit, Polrestabes Surabaya, Surabaya, Indonesia. ${ }^{4}$ Human Genetic Laboratory, Institute of Tropical Disease - International Research Centre, Airlangga University, Surabaya, Indonesia.

Received: 31 October 2017 Accepted: 3 May 2018

Published online: 14 May 2018

\section{References}

Adams SE et al (2017) A randomised clinical study to determine the effect of a toothpaste containing enzymes and proteins on plaque oral microbiome ecology. Sci Rep 7:43344 Available at: http://www.nature.com/articles/ srep43344

Agency for Toxic Substances and Disease Registry, 2003. Public health statement: toxicological profile for fluorides, hydrogen fluoride, and fluorine. Available at: http://www.atsdr.cdc.gov/ToxProfiles/tp11-c1-b.pdf

Alfadaly N, Kassab A, Al Hedaithy F (2016) Determination of DNA profiling of siwak and toothbrush samples used in Kingdom of Saudi Arabia. Egypt J Med Hum Genet 17(4):383-387

Arbeli Z, Fuentes CL (2007) Improved puri ל cation and PCR ampli ל cation of DNA from environmental samples. FEMS Microbiol Lett 272 (2007):269-275. https://doi.org/10.1111/j.1574-6968.2007.00764.x

Chen $\mathrm{H}$ et al (2010) Evaluation of five methods for total DNA extraction from western corn rootworm beetles. PLoS One 5(8):e11963

Chomczynski P et al (1997) DNAzol: a reagent for the rapid isolation of genomic DNA. BioTechniques 22(3):550-553 
Hedman J, Ansell R, Nordgaard A (2010) A ranking index for quality assessment of forensic DNA profiles forensic DNA profiles. BMC Res Notes 3(1):290 Available at: http://www.biomedcentral.com/1756-0500/3/290

Khare $P$ et al (2014) Quantitative and qualitative assessment of DNA extracted from saliva for its use in forensic identification. J Forensic Dent Sci 6(2):81-85 Available at: http://www.pubmedcentral.nih.gov/articlerender.fcgi?artid= 4130022\&tool=pmcentrez\&rendertype $=$ abstract

Lawless, C.J., 2009. Helping with Inquiries: theory and practice in forensic science. Durham theses, Durham University. Available at: http://etheses.dur.ac.uk/ 2098/1/2098_106.pdf

Leary, M. Lou, 2012. DNA for the defense bar. U.S. Department of Justice

National Research Council (2011) Reference Manual on Scientific Evidence 3rd ed. , Washington, DC: The National Academies Press. https://doi.org/10.17226/ 13163

Niemi RM et al (2001) Extraction and purification of DNA in rhizosphere soil samples for PCR-DGGE analysis of bacterial consortia, pp 155-165

Olson ND, Morrow JB (2012) DNA extract characterization process for microbial detection methods development and validation. BMC Res Notes 5(1):1 Available at: BMC Research Notes

Oxford Gene Technology (2011) Understanding and measuring variations in DNA sample quality, pp 1-7 Available at: https://www.ogt.com/resources/ literature/483_understanding_and_measuring_variations_in_dna_sample_ quality. Accessed 23 June 2017

Promega (2014) How do I determine the concentration, yield and purity of a DNA sample? Promega protocols and applications guide, pp 1-3 Available at: https:// worldwide.promega.com/resources/pubhub/enotes/how-do-i-determine-theconcentration-yield-and-purity-of-a-dna-sample/. Accessed 13 Oct 2017

Song GH et al (2015) Effects of fluoride on DNA damage and caspase-mediated apoptosis in the liver of rats. Biol Trace Elem Res 166(2):173-182

Sullivan KM et al (1993) A rapid and quantitative DNA sex test: fluorescencebased PCR analysis of X-Y homologous gene amelogenin. BioTechniques 15(4):636-8, 640-1 Available at: http://www.ncbi.nlm.nih.gov/pubmed/ 8251166. Accessed 21 Dec 2017

Vandewoestyne M, Deforce D (2010) Laser capture microdissection in forensic research: a review. Int J Legal Med 124(6):513-521

Volpe AR et al (1995) Clinical anticaries efficacy of NaF and SMFP dentifrices: overview and resolution of the scientific controversy. J Clin Dent 6:1-28 Available at: http://www.ncbi.nlm.nih.gov/pubmed/8602906. Accessed 17 Dec 2017

Yiamouyiannis, J., 1998. Consumer health articles: FLUORIDE, THE SILENT KILLER. Available at: http://www.consumerhealth.org/articles/display.cfm?lD= 19990303222823. Accessed 4 Oct 2017

Zhang M et al (2008) Effects of fluoride on DNA damage, S-phase cell-cycle arrest and the expression of NF-KB in primary cultured rat hippocampal neurons. Toxicol Lett 179(1):1-5

\section{Submit your manuscript to a SpringerOpen ${ }^{\circ}$ journal and benefit from:}

- Convenient online submission

- Rigorous peer review

- Open access: articles freely available online

- High visibility within the field

Retaining the copyright to your article

Submit your next manuscript at $\boldsymbol{s p r i n g e r o p e n . c o m ~}$ 